Document downloaded from:

http://hdl.handle.net/10251/99865

This paper must be cited as:

Gutiérrez-Martínez, MDR.; Muñoz Guerrero, HP.; Alcaina-Miranda, MI.; Barat Baviera, JM. (2014). Protein removal from waste brines generated during ham salting through acidification and centrifugation. Journal of Food Science. 79(3):326-332. doi:10.1111/17503841.12373

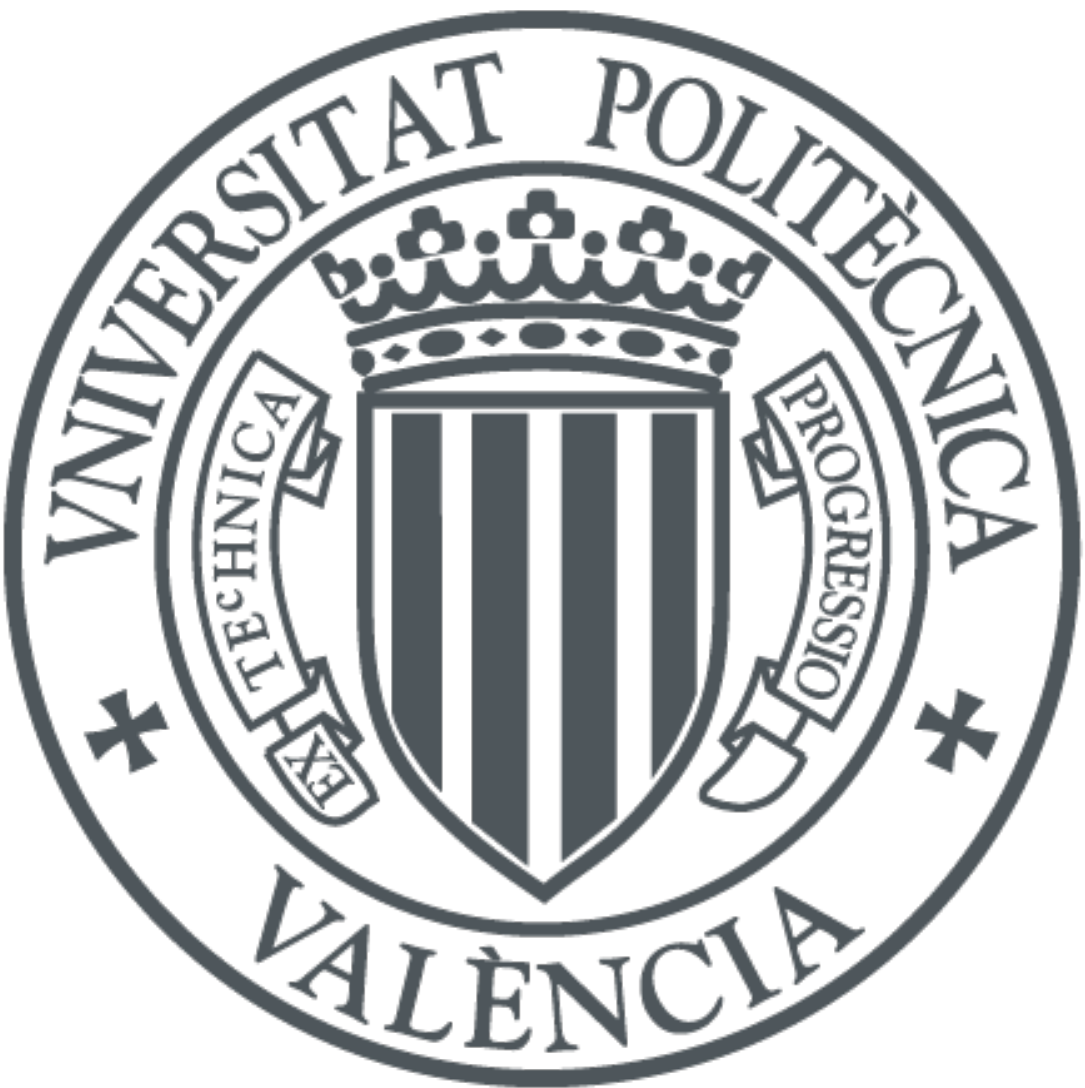

The final publication is available at

http://doi.org/10.1111/1750-3841.12373

Copyright Blackwell Publishing

Additional Information 


\section{Protein removal from waste brines generated during ham salting through acidification and centrifugation}

\begin{tabular}{|r|l|}
\hline Journal: & Journal of Food Science \\
\hline Manuscript ID: & Draft \\
\hline Manuscript Type: & 5 Food Engineering and Physical Properties \\
\hline Complete List of Authors: & $\begin{array}{l}\text { Gutierrez, Rosario; Politechnic University of Valencia, Food Science and } \\
\text { Technology } \\
\text { Muñoz-Guerrero, Hernan; Universidad de Antofagasta, Departamento de } \\
\text { Alimentos } \\
\text { Alcaína-Miranda, M. Isabel; Politechnic University of Valencia, } \\
\text { Departamento de Ingeniería Química y Nuclear } \\
\text { Barat, Jose; Politechnic University of Valencia, Food Science and } \\
\text { Technology }\end{array}$ \\
\hline Keywords: & $\begin{array}{l}\text { residues, mathematical modeling, food engineering, salt, osmotic } \\
\text { dehydration }\end{array}$ \\
\hline
\end{tabular}

\section{SCHOLARONE}

Manuscripts 
1 Protein removal from waste brines generated during ham 2 salting through acidification and centrifugation

3 Gutiérrez-Martínez ${ }^{2}$, M.R.; Muñoz-Guerrero ${ }^{3}$, H.; Alcaína-Miranda ${ }^{2}$, M.ı.; Barat ${ }^{{ }^{*}}$, 4 J.M.

5

$6 \quad{ }^{1 *}$ Departamento de Tecnología de Alimentos, Universitat Politècnica de 7 València, Camino de Vera $s / n$, Valencia (46022), Spain. E-Mail:

8 imbarat@tal.upv.es

$9 \quad{ }^{2}$ Departamento de Ingeniería Química y Nuclear, Universitat Politècnica de 10 València. Camino de Vera s/n, Valencia (46022), Spain. E-Mail:

11 magumar@doctor.upv.es

$12{ }^{3}$ Departamento de Alimentos, Facultad de Recursos del Mar, Universidad de 13 Antofagasta. Avda. Angamos 601, Antofagasta (1270300), Chile. E-Mail:

14 hmunoz@uantof.cl

*Author for correspondence: Jose M Barat

E-mail jmbarat@tal.upv.es

Phone: +34 963877365

Fax : +34 963877369 


\section{ABSTRACT}

28 The salting step in food processes implies the production of large quantities of waste brines having high organic load, high conductivity and other pollutants with high oxygen demand. Direct disposal of the residual brine implies salinization of soil and eutrophication of water. Since most of the organic load of the waste brines comes from proteins leaked from the salted product, precipitation of dissolved proteins by acidification and removal by centrifugation is an operation to be used in waste brine cleaning.

The aim of this study is optimizing the conditions for carrying out the separation of proteins from waste brines generated in the pork ham salting operation, by studying the influence of $\mathrm{pH}$, centrifugal force and centrifugation time. could be used for waste brine protein removal. acidification. 


\section{INTRODUCTION}

53 Dry-cured ham is the most important processed meat product in Spain and well known worldwide for its excellent sensory characteristics (Toldrá, 2010). traditions of each area of production (Toldrá, 2010), however there are some

common stages: pre-conditioning of the raw material, curing, salting, postsalting or settlement, drying, aging or maturation and refinement (Barat et al., 2004). The process generates solid and liquid waste (sewage). The dry-salting step is mainly accomplished in plastic or metallic containers that allow the drainage of the generated brine (Barat et al., 2006). The waste brine is composed primarily by water, minerals, blood, proteins and other soluble compounds (Barat et al., 2006). The waste brine exceeds most of the limits permitted by law for direct disposal, and thus it must be treated before disposal. Nevertheless, the treatment of the waste brine can't be done through conventional treatments because of its very high conductivity as a consequence of the high salt content (Barat et al., 2006). Thus it must be managed as a special waste, with an increase in the production cost in addition to the environmental impact.

Figure 1 shows the general dry-salting process of Spanish dry-cured ham, were the wastes generated during the process have been highlighted. Figure1.

Barat et al. (2006) estimated the production of saturated residual brine during Spanish dry-cured ham production in the year 2003, which was in the 
75

range from 29000 to $31700 \mathrm{~m}^{3}$ / year, corresponding to nearly the $10 \%$ of the weight of the raw hams.

Due to the large variety of stages involved in the overall process, the residual brine has a high content of pollutants. The levels of chlorides, chemical oxygen demand (COD), nitrate and total suspended solids obtained exceeded the limits established by law (L.BOP, 1995) (Barat et al., 2006) for their direct discharge, as they are likely to cause harmful effects to the environmental status of waters. The main problems are related to eutrophication due to the presence of salts such as nitrates and phosphates; unfavourable oxygen balance due to the presence of organic compounds, and soil and water salinization due to the high electrical conductivity, as a consequence of the high concentration of salts (Buckley et al., 1987).

Waste brines coming from ham salting are rich in proteins, since the raw ham contains around $20 \%$ of proteins, free amino acids, dipeptides, and nucleotides (Warris, 2003). The proteins found in the brine are soluble in concentrated salt solutions and myofibrillar type (Lawrie,1998) such as actin, tropomyosin, troponin, $\alpha$-actinin, $\beta$-actinin, myosin, protein $C$, protein M. Most proteins are denatured at relatively low temperatures $\left(<60^{\circ} \mathrm{C}\right)$ and also in acidic conditions, a fact used to produce protein precipitation in the brine to treat (Cheftel, 1989).

\subsection{Waste brine treatment alternatives}

To minimize the environmental impact of waste brines, various techniques have been used such as natural evaporation, forced evaporation, or vacuum evaporation (Diez et al., 2000). One disadvantage of this approach is that the 
100 residual solid obtained must be discharged as a special polluting waste, and the 101 high consumption of resources, especially energy.

102 Another alternative technique is the regeneration of the brine for reuse 103 (Barat et al., 2005). This approach consists in the removal of the existing 104 oxygen demand (COD), nitrates and fats.

\subsection{Brine characterization analysis}

The main physicochemical properties of the waste brine were determined, as well as those of the main parameters related to their polluting load.

Those determinations were: chloride, $\mathrm{pH}$, conductivity, total solids, chemical 
A 1:2000 dilution of the brine was done to determine the chloride content by means of a chloride analyzer (CIBA Corning Mod 926) (Barat et, al., 2006). A dilution of 1:1000 was used for determination sample $\mathrm{pH}$ and conductivity, and was measured with a pH meter CRISON® model MM 40 (CRISON Instrument SA, Barcelona, Spain) with a PT100 sensor for temperature compensation.

The COD measurement was carried out by photometric determination of the chromate concentration two hours after oxidation with potassium dichromate, sulphuric acid and silver sulphate, using a photometer NANOCOLOR model 300D (Macherey-Nagel GmbH \& Co. KG) and Test 0-33 (NANOCOLOR COD 300 - DIN 34409-H41-1 and in accordance with ISO 15705). Since chloride content higher than $1500 \mathrm{mg} / \mathrm{L}$ causes interference in the method, it was necessary to dilute the sample (dilution 1:50 v/v). For the determination of nitrates in the brine a photometer NANOCOLOR $® 300 D$ (MachereyNagel GmbH\& Co. KG) was used, with the kit reagents and Test 064 (NANOCOLOR $®$ Nitrate 50. DIN 38 405-D9-3). This analysis is based on the photometric determination with 2,6-dimethylphenol, in a mixture of sulfuric /phosphoric acid. A dilution of 1:2000 brine was done to ensure that the sample is within the range where there was no interference, both from chlorine and nitrite. Total solids in the brine were determining by means of the method APHA $2540 \mathrm{~B}$ and fat content was determined using an automatic unit Soxhlet ${ }^{\mathrm{TM}} 2055$ (APHA 5520D, 1998) FOOs, Hillerod, Denmark.

Analytical determinations were done in triplicate and the Statgraphics $₫$ Plus 5.1 sotware was used to do the statistic of the obtained results.

\subsection{Acidification and centrifugation experiments}


Denaturation of proteins in the residual brine was carried out by means of 150 acidification (Lawrie, 1998). Considering that the isoelectric point of proteins is 151 in the range of $\mathrm{pH}$ from 4.5 and 5 (Flores, 1997), the waste brine $\mathrm{pH}$ was 152 adjusted from the initial brine $\mathrm{pH}(6.2 \pm 0.01)$ to $2,3,4$ and 5 by means of concentrated hydrochloric acid $(5 \mathrm{~N})$ to avoid dilution and introducing elements that are not naturally present in the brine.

Protein removal from the acidified brine was studied by means of centrifugation. Four centrifugation times were used in the study (5, 10, 15 and 20 minutes) and 5 centrifugation speeds (1000, 3000, 6000, 10000 and 15000 rpm).

A factorial design was used (80 combinations) and three replications were done at every combination. At every studied point, 15 milliliters of the acidified brine solution were used.

At every point, the collected pellet was weighted, and its moisture determined by drying at $104^{\circ} \mathrm{C}$ for 24 hours (according to the official standard ISO R-1442). The salt content of the dehydrated pellet was calculated considering that the salt concentration of the retained liquid of the pellet was the same than that of the supernatant.

The centrifugation of the brine was done by means of a BL MEDIFRIGER 7001085 centrifuge. The relative acceleration at every centrifugation speed was determined by means of equation 1 :

\section{1 where:}

$$
\mathrm{RCF}=0.0000118 \cdot r \cdot v^{2}
$$

$172 \mathrm{RCF}=$ Relative acceleration in $\mathrm{g} ; \mathrm{RCF}_{\text {maximum }}=19584 \mathrm{~g}$

$173 \mathrm{r}=$ Radius of rotation $(\mathrm{r}=8.2 \mathrm{~cm})$ 
$174 \mathrm{~V}=$ Spin speed $(\mathrm{rpm}) ;$ Spin speed maximum $=15000 \mathrm{rpm}$

175 Table 1 shows the equivalence between spin speed and relative 176 acceleration (RCF) calculated by means of equation 1.

177

\section{$178 \quad \underline{\text { Table } 1}$}

179

180 bicinchoninic acid method (microplate) (Laemmlí, 1970).

\subsection{Statistical analysis}

185 The experimental design and statistical analysis of the results was carried

\section{RESULTS AND DISCUSSION.}

\subsection{Waste brine characterization} seen in table 2 .

\section{Table 2.}


The maximum values accepted by Spanish Laws (R.D.606/1993) for direct disposal of effluents are shown in the third column of table 2. As it can be observed, all the analyzed parameters had higher values than the accepted by laws for direct disposal. As stated in the introduction section, the most remarkable fact is the big contamination with organic compounds combined with the very high conductivity of the waste brines.

Considering that all the chlorides present in the brine come from the $\mathrm{NaCl}$ use for ham salting, it can be confirmed that the residual brine collected from the salting containers is saturated as expected. In addition to the very high salt content of the brine, a significant concentration of nitrates was determined, which indicates the partial leakage of the used nitrates in the nitrification stage. $\mathrm{pH}$ and time. respectively.

\section{$\underline{\text { Table } 3}$}


222 It can be observed a good fitting of the model for all the other experimental 223 conditions except for 1000 r.p.m.. In all cases the obtained precipitate was 224 dependant of $\mathrm{pH}$ and centrifugation time. In case of centrifugation at 1000 r.p.m. 225 the bad fitting was due the very low precipitate collected at any $\mathrm{pH}$ or 226 centrifugation time.

227 The response surfaces obtained from the fitted models for $3000,6000,10000$ 228 annd $15000 \mathrm{rpm}$ can be observed in figure 2.

\section{Figure 2.}

231

\section{Figure 3}


Attending to that result, it seems that a $\mathrm{pH}$ of 3 would be the best value to be employed in an industrial treatment, since the protein separation is quite high, 248 as much as at $\mathrm{pH} \mathrm{2,,} \mathrm{with} \mathrm{less} \mathrm{acid} \mathrm{to} \mathrm{be} \mathrm{added,} \mathrm{lower} \mathrm{dilution} \mathrm{of} \mathrm{the} \mathrm{waste}$ brine and better preservation of the equipment than with $\mathrm{pH} 2$. It is known that at low $\mathrm{pH}$ values the corrosion rate increases exponentially with $\mathrm{pH}$ decrease (DOE-HDBK-1015, 1993).

When the centrifugation speed increased, the maximum weight fraction of collected pellet was achieved at shorter time. In some experimental conditions (6000 rpm and $\mathrm{pH} 2$ ), a decrease of the collected pellet can be observed when the centrifugation time increases. It could be explained by the compaction of the pellet, thus reducing the retained brine in the pellet and as a consequence of that the water content. To confirm this hypothesis, the protein content in the supernatant at a pH 3 and the dry pellet were determined.

In the previous figure it can be observed that the maximum precipitate fraction obtained at centrifugation speeds of $3000,6000 \mathrm{rpm}$ at $\mathrm{pH}$ values 2 and 3 , was achieved at 20 and 5 minutes, respectively.

Figure 4 shows the total quantity of dry pellet collected after centrifugation and the percentage of removed protein from the supernatant working at $\mathrm{pH} 3$ for

5 and 20 minutes. As it can be seen, the maximum protein removal from the brine was close to $90 \%$ of the initial content. This value is an asymptotic one and no significant differences were observed depending on the centrifugation time. Attending to this observation, it seems that a further protein cleaning should have to be attained by using filtration techniques.

On the other hand, when the quantity of collected dry solid is analyzed, it is confirmed an initial increase in the collected pellet when the centrifugation 
271 speed increases simultaneously with the increase in protein removal from the

272 brine. Nevertheless, once a maximum value is achieved, a decrease in the

273 collected dry pellet is observed, even maintaining the quantity of removed

274 proteins, and confirming the mentioned hypothesis that points out towards a

275 compactation of the pellet when the centrifugation speed and time increases,

276 with no increase in the protein removal.

277

278

279

280

281

282

283

284

285

286

287

288

289

290

291

292

293

294

295

\section{Figure 4}

\subsection{Influence of centrifugation time and speed to $\mathrm{pH} 3$.}

As mentioned in the previous section, it was considered the $\mathrm{pH} 3$ as the optimum for protein removal. That's why the study of the influence of centrifugation time and speed was done at that $\mathrm{pH}$ value. The wet pellet weight fraction collected at $\mathrm{pH} 3$ (with standard deviation bars) depending on the centrifugation speed and time can be observed in figure 5.

\section{Figure 5}

As a general pattern it can be observed that the collected pellet achieved the maximum values at centrifugation speeds of 6000 and $10000 \mathrm{rpm}$, with a drastic decrease at a centrifugation rate of $15000 \mathrm{rpm}$, pointing out to the compaction of the collected pellet occurred with time and increasing centrifugation speed.

Figure 6, shows the collected wet pellet at $\mathrm{pH} 3$ at every centrifugation time, depending on the centrifugation speed. It can be clearly seen that no influence of centrifugation time exists at a centrifugation speed of 1000 , probably because it 
296

297

298

299

300

301

302

303

304

305

306

307

308

309

310

311

312

313

314

was a too small speed for collecting the denatured proteins. On the contrary, a clear influence of centrifugation time was observed form 3000, 6000 and 10000 rpm speeds, with a common behaviour, reaching a maximum in the collected pellet at a certain time, and decreasing the collected pellet at further time, due to the compaction action previously mentioned. In case of $15000 \mathrm{rpm}$, the maximum compaction would be achieved before the 5 minutes, indicating that no benefits would be achieved at longer centrifugation times except for a reduction of the retained brine in the precipitate.

\section{Figure 6}

It can be seen that for the same centrifugation time, the maximum collected pellet is achieved at lower centrifugation speed than the maximum one, giving support to the compaction of the brine, which was independent of time for the maximum speed.

\section{Conclusions.}

The use of acidification of residual brine coming from pile salting during Spanish dry-cured ham production is an effective technique for protein removal.

The best $\mathrm{pH}$ value to be used in an industrial process seems to be 3 , because a large quantity of proteins is removed while the $\mathrm{pH}$ is no very low. The industrial processing should have to be followed by the neutralization of the supernatant.

The obtained results indicate that almost $90 \%$ of the proteins from the brine can be removed by acidification followed by centrifugation. A further protein 
321 removal from the brine should have to be achieved by using filtrating

322 techniques, which efficiency could be highly improved as a consequence of the

323 previous treatment through acidification and centrifugation. Further studies are

324 needed to confirm this aspect.

325

Acknowledgements

327 We would like to thank the Spanish Government (MCYT) and the EU 328 (FEDER program) for the financial support of the project (AGL2004-05064$329 \mathrm{C} 02)$.

\section{Bibliography.}

332

333

334

335

336

337

Akili D.Khawaji, Ibrahim K Kutubkhanah and Jong-Mihn Wie (2008), Advances in seawater desolation technologies, Desalination,221, 47-49.

Barat J. M, Grau R., Pagán-Moreno M.J. and Fito P. (2004), Replacement of pile by simultaneous brine thawing-salting in Spanish cured ham manufacturing, Meat Science, 66, 603-608

Barat J.M., Grau R., Ibañez J. B. and Fito P.(2005) Post salting studies in Spanish cured ham manufacturing. Time reduction by using brine thawingsalting., Meat Science, 69, 201-208.

Barat J.M., Vidal-Brotóns D., López-Pascual E.,.Gras M.L (2006) Quantification and kinetics of the residual brine generation during ham and shoulder pile salting, Meat Science, 73, 576-580.

Bes-Piá A., Cuartas-UribeB., Mendoza-Roca J.A., Galiana-Alexandre M.V., Iborra Clar M.I., Alcaina-Miranda M.I.(2008). Pickling wastewater reclamation by means of nanofiltration, Desalination, 221,225-2 
346 Buckley, C.A; Simpson,A.E; Kerr,C.A.; Schutte,C.F. The treatment and 347 disposal of waste brine solutions, Desalination 1987, 67,0, 431-438.

348 Cheftel J.C. (1989), Food Proteins.Biochemistry, functional properties nutritional 349 value, chemical modifications. Edition Acribia 141-165

350 Cruz J ( 2003) "Analysis of the production and marketing of ham in Spain" $351 \quad$ Eurocarne 113,page 23-30

352 Cuartas-Uribe B, Alcaína-Miranda M.I. , Soriano-Costa E. and Bes-Piá A. 353 (2007),Comparison of the behavior of two Nanofiltration Membranes for 354 sweet whey demineralization, Journal of Diary Science,90,1094-1101

355 Diez, V., Del Pozo, R., Salazar, G., García, L.,( 2000)”, Wastewater Meat 356 Industry, treatment options and selection criteria. Eurocarne 87,35-46.

357 Doe fundamentals handbook chemistry. (1993) DOE HDBK, 1015/ 1-93, $358 \quad$ Volume 1,2 January 1993

359 Flores J.(1997). Mediterranean vs. northern European meat products. 360 Processing technologies and main differences, Food Chemistry, 59,505-510 361 Gallard Jornet, L;Escriche Roberto , I; Fito Mauppey, P (2005), The salting of 362 fish, a tradition in the Mediterranean diet, Polytechnic University of $363 \quad$ Valencia. 111

364 Joo,S.T,.Kauffman, R.G.Kim, B.C., G.B.(1999).The relationship of sarcoplasmic 365 and myofibrillar protein solubility to colour and water-holding capacity in 366 porcine longissimus muscle. Meat Science 52, 291-197

367 Laemmlí UK,(1970). Cleavage of structural proteins during the assembly of the 368 head of bacteriophage T4. Nature, 227,680-685

369 Lawrie, R.A.,(1998)"Meat Science"3ª edition, Ed, Acribia , Zaragoza. 123 
370 Lee Nohun, Amy Gary, Groué Jean Philippe and Buisson Herve,

371 (2004), Identification and understand ding of fouling in low pressure

372 membrane (MF/UF) filtration by natural organic matter (NOM)Water

373 Research, 38,4511-4523

374 Li J.,Shi Y.M., Whan R.S.,Li X.D.,Xie G.F.,(2009) Analysis of the performance

375 of a sintered stainless steel wire mesh filter for cryogenic liquid

376 purification., Cryogenics,49,27-37

377 Ministry of the environment program A.G.U.A. Proceedings for the management

378 and use of water

379 Provincial Legislation Official Gazette ( L. BOP 162);(10/07/1995)

380 Toldrá F and Aristoy C ,Dry-Cured Ham, In Toldrá .,editor, Handbook of Meat

381 Processing, first ed,IOWA:WILEY-BLACKWELL;2010,354-357.

382 Ventanas J. (2001). "Technology Iberian ham. In traditional systems the 383 rational explotation of the flavor and aroma“. Editions Mundi-prensa

384 Vineet K.Gupta, Nishith Verma (2002), Removal of volatile organic compounds

385 by cryogenic condensation followed by adsorption, Chemical Engineering

386 Science, 57,2679-2926.

387 Warris, P,D.(2003). Meat Science, Ed. Acribia Zaragoza. 


\section{Figure index}

396 Figure1. General process for the preparation of Spanish dry-cured ham 397 (adapted from Toldrá and Aristoy, 2010).

398 Figure 2. Evolution of the wet pellet weight fraction $\left(x^{p p} g / g\right)$ as a function of $p H$ 399 and centrifugation time (t) for 3000 (a), 6000(b), 10000(c) and 15000 rpm (d) Figure 3. Protein concentration in the supernatant of acidified brine after 401 centrifugation at $6000 \mathrm{rpm}$ for 5 minutes.

402 Figure 4. Percentage of protein removal from the supernatant and collected dry pellet different centrifugation speeds at 5 (a) and 20 (b) minutes.

404 Figure 5. Evolution of the wet pellet weight fraction $(\mathrm{g} / \mathrm{g}$ ) ( with standard 405 deviation bars) at different centrifugation time and speed at $\mathrm{pH} 3$.

406 Figure 6. Evolution of the pellet weight fraction $(\mathrm{g} / \mathrm{g})$ colleted for constant 407 centrigugation times at different centrifugation speed and $\mathrm{pH} 3$. 
$421 \quad$ Figure 1

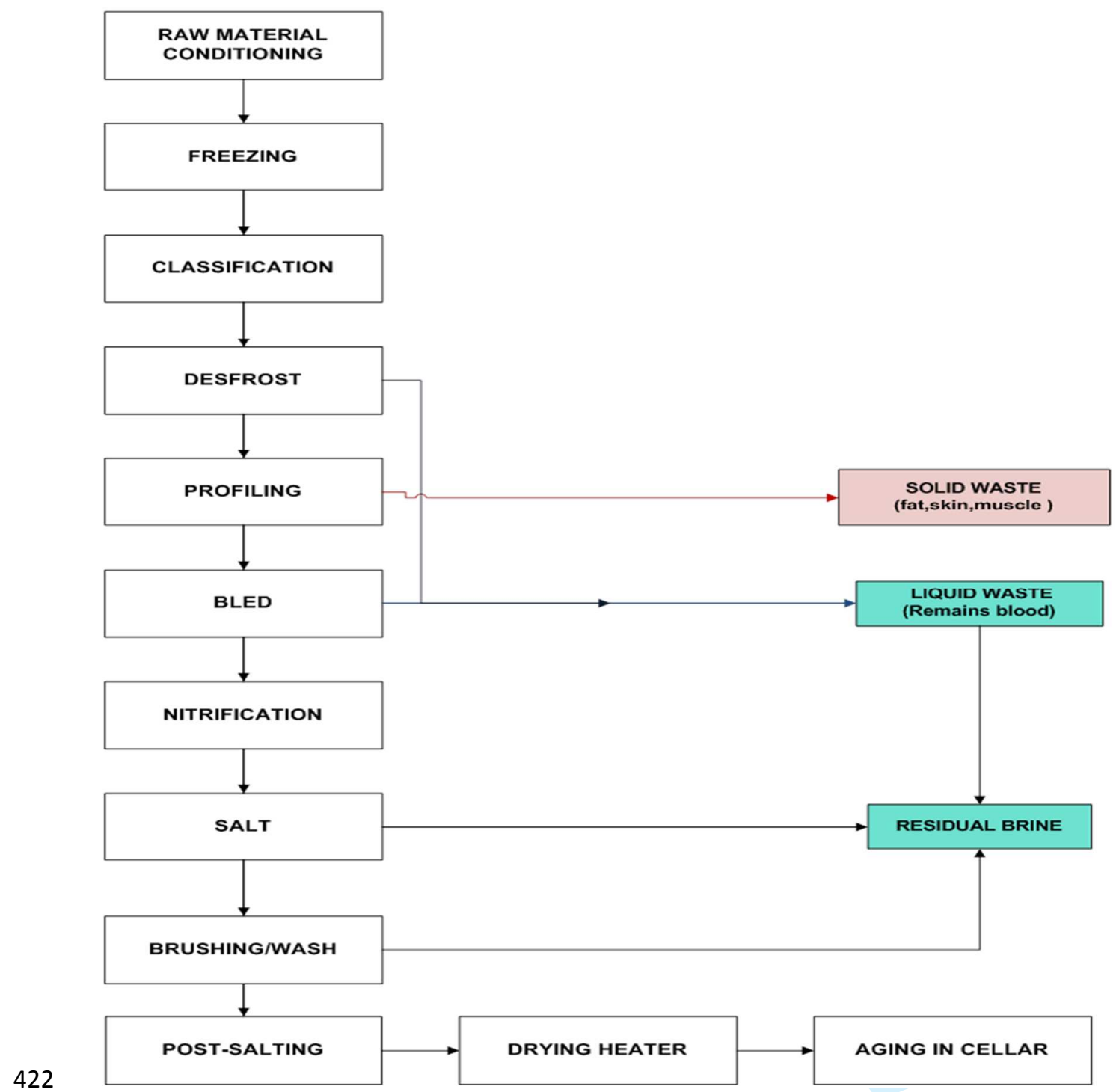


$430 \quad$ Figure 2

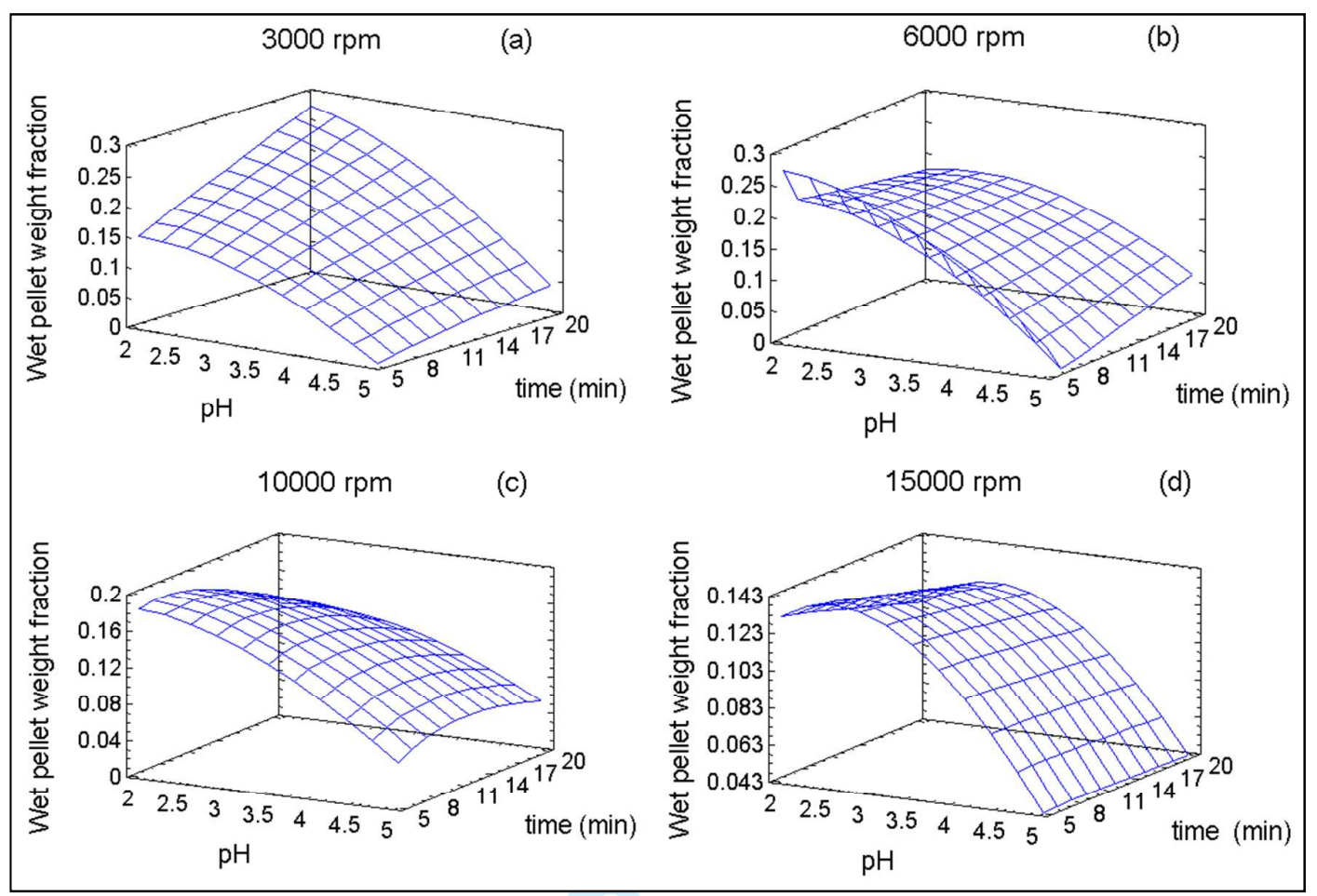

431

432

433

434

435

436

437

438

439

440 
$441 \quad$ Figure 3

442

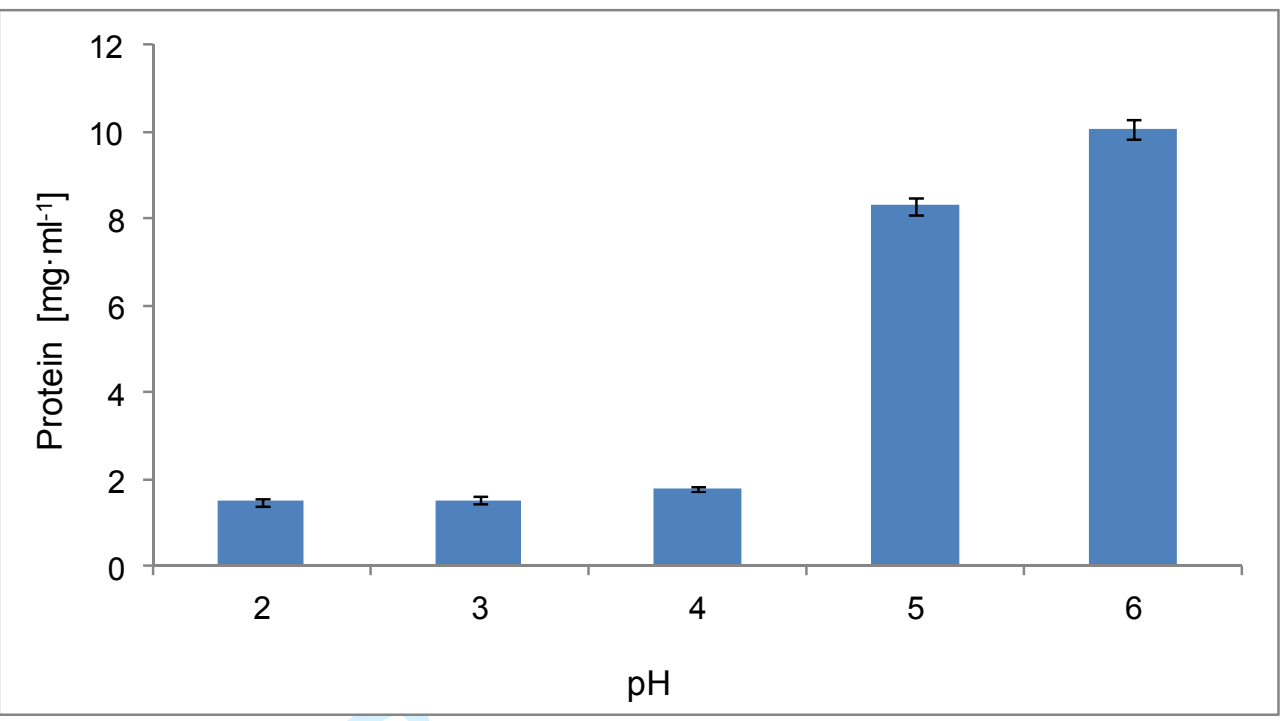

443

444

445

446

447

448

449

450

451

452

453

454

455

456

457

458 
459

$460 \quad$ Figure 4.

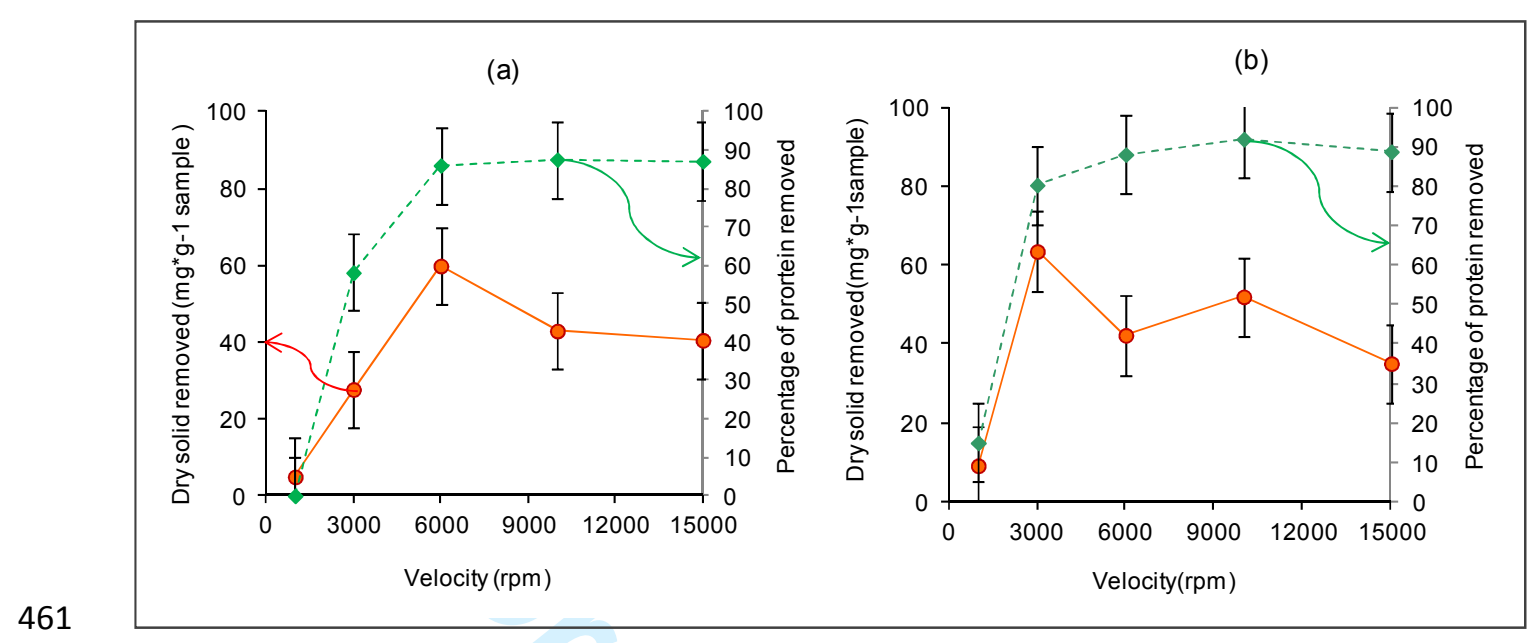

462

463

464

465

466

467

468

469

470

471

472

473

474

475

476

477 
478

$479 \quad$ Figure 5

480

481

482

483

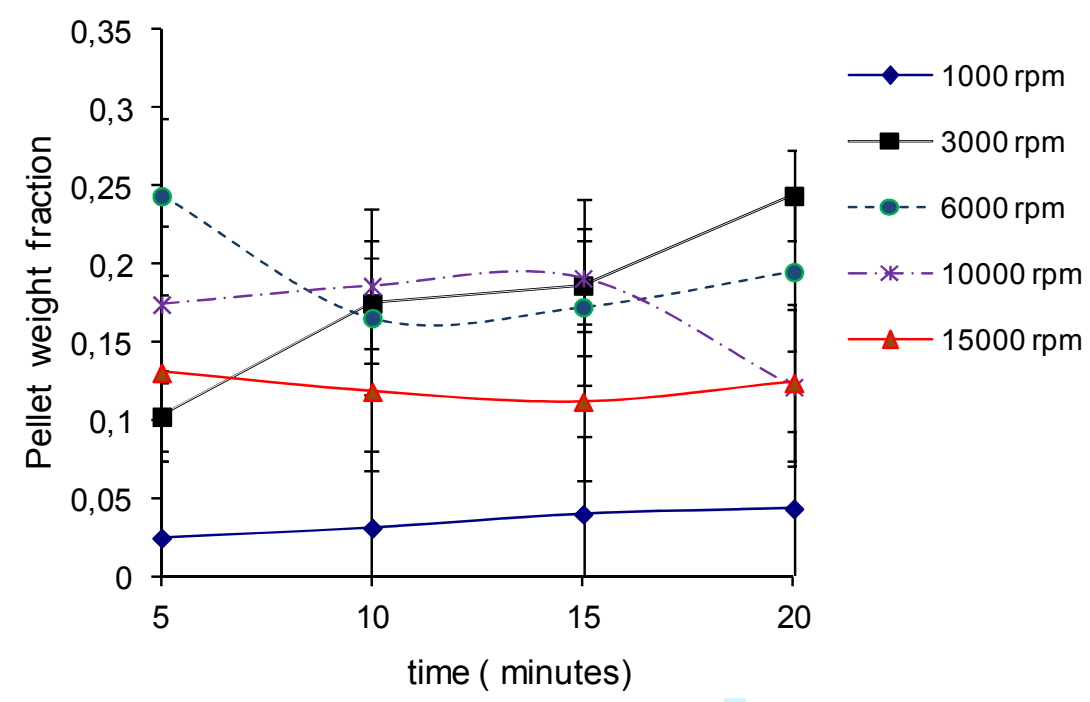

484

485

486

487

488

489

490

491

492

493

494

495 
496

497 Figure 6

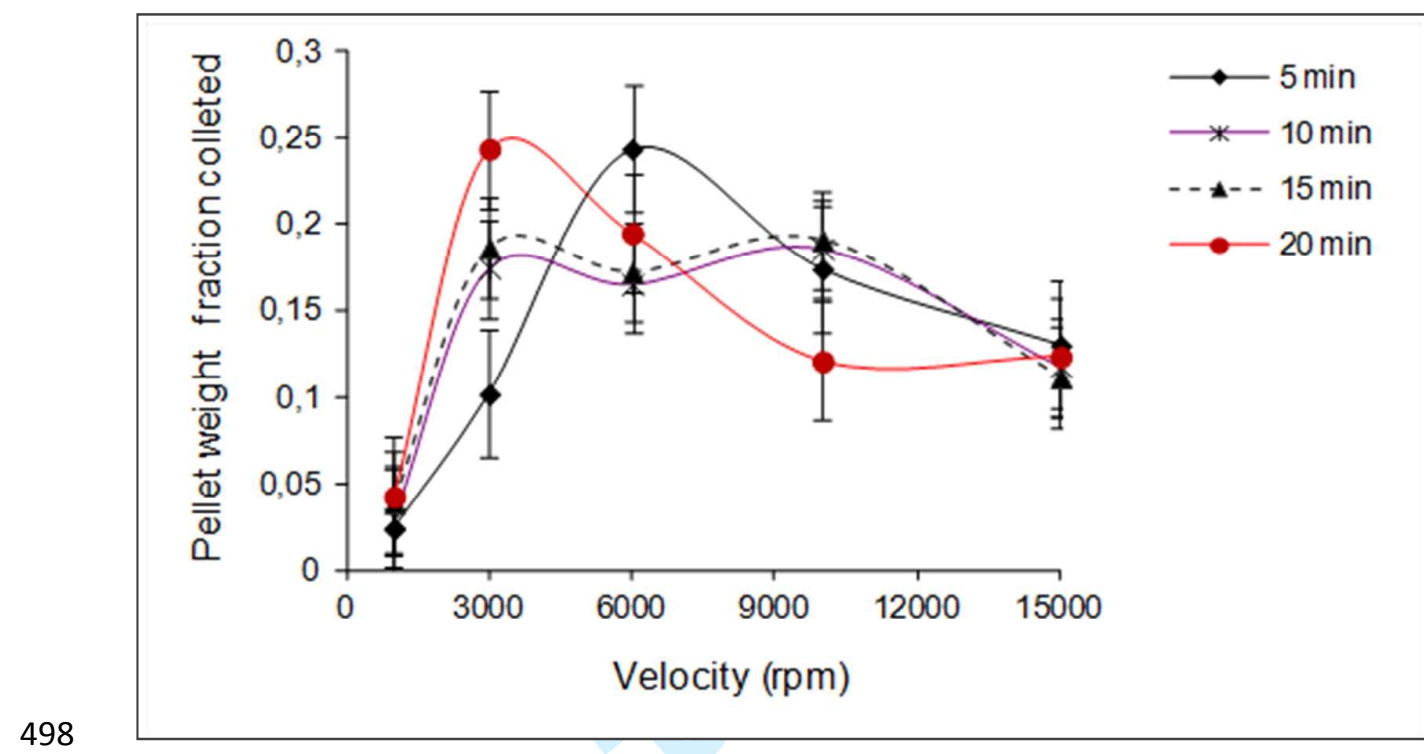

499

500

501

502

503

504

505

506

507

508

509

510

511

512

513 
514

515 Index table

516 Table1. Equivalence of spin speed used in the experiments and relative

517 acceleration (g)

518 Table 2. Physicochemical properties of the waste brine used in the study.

519 Table 3. The models and the regression coefficients at different velocities

520

521

522

523

524

525

526

527

528

529

530

531

532

533

534

535

536

537

538 
541 Table 1

\begin{tabular}{|c|c|c|c|c|c|}
\hline Spin speed (rpm) & 1000 & 3000 & 6000 & 10000 & 15000 \\
\hline Relative & 92 & 825 & 3300 & 9168 & 20627 \\
acceleration (g) & & & & & \\
\hline
\end{tabular}

542

543

544

545

546

547

548

549

550

551

552

553

554

555

556

557

558

559

560 
562 Table 2

\begin{tabular}{|c|c|c|c|}
\hline Analysis & $\begin{array}{c}\text { Values of } \\
\text { analysed } \\
\text { waste brine }\end{array}$ & $\begin{array}{c}\text { Maximum accepted } \\
\text { values for disposal } \\
\text { from Spanish Laws } \\
\text { (R.D. 606/1993) }\end{array}$ & Analytical method \\
\hline pH & $6.2 \pm 0.01$ & $5.5-9.5$ & pH meter \\
CRISON MM40
\end{tabular}




\section{Table 3}

\begin{tabular}{|c|c|c|}
\hline rpm & Model* $^{*}$ & $\begin{array}{c}\text { Regression } \\
\text { coefficient }\left(\mathbf{R}^{2}\right)\end{array}$ \\
\hline 1000 & $\begin{array}{c}x^{p p}=28.14 \cdot p H^{0,56}-0.24 \cdot t^{-0,26}+7.62 \cdot 10^{-4} \cdot p H \\
\cdot t-0.11 \cdot p H-4.09 \cdot 10^{-3} \cdot t\end{array}$ & 7.2 \\
\hline 3000 & $\begin{array}{c}x^{p p}=0.63 \cdot p H^{0,64}-0.29 \cdot t^{-0,06}-1.89 \cdot 10^{-3} \cdot p H \\
\cdot t-0.30 \cdot p H+0.01071 \cdot t\end{array}$ & 89.9 \\
\hline 6000 & $\begin{array}{c}x^{p p}=2.64 \cdot p H^{0.95}+3.29 \cdot 10^{9} \cdot t^{-15.44}+25,48 \cdot p H \\
\cdot t-2.43 \cdot p H-7.83 \cdot 10^{-3} \cdot t\end{array}$ & 88.8 \\
\hline 10000 & $\begin{array}{c}x^{p p}=1.45 \cdot p H^{0,94}+0.18 \cdot t^{0.96}+1.51 \cdot 10^{-3} \cdot p H \cdot t \\
-1.31 \cdot p H-0.16 \cdot t\end{array}$ & 78.2 \\
\hline 15000 & $\begin{array}{c}x^{p p}=1.01 \cdot p H^{0.832}-0.22 \cdot t^{-0.004}+5.50 \cdot 10^{-4} \cdot p H \\
\cdot t-0.72 \cdot p H-0.00287 \cdot t\end{array}$ & 91.0 \\
\hline \multicolumn{3}{|c|}{${ }^{*}\left(x^{p p}=\right.$ wet pellet weight fraction $-g / g-, t=$ time $\left.(\min )\right)$} \\
\hline & & \\
\hline
\end{tabular}

